\title{
Impact of atmospheric precipitation on the volume of wastewater inflowing to the treatment plant in Nowy Targ
}

\author{
Elwira Nowobilska-Majewska ${ }^{1}$, Tomasz Kotowski ${ }^{1}$, and Piotr Bugajski ${ }^{1{ }^{*}}$ \\ ${ }^{1}$ Department of Sanitary Engineering and Water Management University of Agriculture in Kraków, Mickiewicza 24/28, 30-059 \\ Kraków, Poland
}

\begin{abstract}
The study determines the impact of precipitation on the amount of wastewater flowing into the treatment plant in Nowy Targ. The research period covered the years 2016 and 2017, in which the amount of precipitation and average daily wastewater inflows (during the so-called dry period, i.e. days without precipitation and in the so-called wet period, i.e. days with precipitation) were analyzed. The research period was divided into 5 characteristic ranges in terms of the amount of precipitation. It was found that on days with different intensity of precipitation, the amount of rainwater (in the total amount of wastewater flowing into the treatment plant) ranges from $14.2 \%$ to $32.5 \%$. Taking into account the absolute values, it was found that the average daily amount of wastewater inflow on days with precipitation was from 14361 to $18248 \mathrm{~m}^{3} \cdot \mathrm{d}^{-1}$ compared to wastewater inflow on days without precipitation $\left(12323 \mathrm{~m}^{3} \cdot \mathrm{d}^{-1}\right)$. The obtained test results should be a signal for sewage network operators for the performance of intensive and effective actions aimed at eliminating illegal connections of drain pipe for rainwater and yard drains to sanitary collectors and the replacement combined sewer system to distribution sewer system in the city of Nowy Targ.
\end{abstract}

\section{Introduction}

One of the basic issues of the proper functioning of a sewage treatment plant is the correct exploitation of the sewage network [1-2]. Inflows of other types of wastewater to the sewage system than domestic wastewater negatively affect the mechanical and biological processes occurring in the technological process of the treatment plant [3-4]. One of the common situations is the phenomenon of illegal discharge of rainwater into sanitary sewage systems [5]. As a result of this phenomenon, during the period of precipitation or snowmelts, the amount of treated wastewater increases. For economic reasons, the increased amount of wastewater increases the costs of wastewater treatment. However, for environmental reasons, this affects the inability to supply groundwater with rainwater in the drainage basin - therefore, their level decreases [6]. The publication is a contribution to the discussion regarding counteracting the common phenomenon of illegal connection of drain pipe for rainwater to sanitary sewage systems.

\section{Material and methods}

The purpose of the study was to determine the impact of precipitation in the sewage system in Nowy Targ on the amount of wastewater flowing into the treatment plant. Tests of daily wastewater outflow were conducted in the period from $01 / 01 / 2016$ to $31 / 12 / 2017$. Due to the fact that (compared to 2016) in 2017 there was no increase in the number of sewage connections in the sewage system, the period of two years (i.e. 731 days) was adopted as homogeneous. Measurement of sewage outflow intensity was tested with the use of an ultrasonic level probe (Waterpilot FMX 167) located in an open channel above the triangular dumper behind the technological line. The amount of precipitation in particular days was determined on the basis of indications of the tippingbucket rain gauge installed in the analyzed sewage basin. According to the recommendations of Kaczor [7], daily wastewater inflows were assigned to dry or wet weather (respectively). A given day of the year was classified as dry weather if during its duration and within five preceding days there was no precipitation or if the precipitation did not exceed $1 \mathrm{~mm}$. The average daily outflow of wastewater during rainless (dry) weather was used to determine the average amount of the so-called proper wastewater, i.e. wastewater without extraneous waters. According to Chmielowski [8], in the case of wet weather (i.e. days with precipitation), five characteristic groups were generated:
A - from 0.1 to $5.0 \mathrm{~mm} \cdot \mathrm{d}^{-1}$,
B - from 5.1 to $10 \mathrm{~mm} \cdot \mathrm{d}^{-1}$,
C - from 10.1 to $15.0 \mathrm{~mm} \cdot \mathrm{d}^{-1}$,
D - from 15.1 to $20.0 \mathrm{~mm} \cdot \mathrm{d}^{-1}$,
E - above $20.0 \mathrm{~mm} \cdot \mathrm{d}^{-1}$.

In the analytical part, two parameters were calculated. They described the amount of extraneous waters (rainwater) inflowing in the total amount of wastewater [9]. The first parameter is $\mathrm{Q}_{\mathrm{dp}}$. It determines the volume of penetrating (rainwater) in the total amount of

*Corresponding author: p.bugajski@urk.edu.pl 
wastewater. Thus, during wet weather, the volume of extraneous wasters in a given day was calculated according to the formula (1).

$$
Q_{d p}=Q_{d m}-Q_{d s}
$$

where:

$\mathrm{Q}_{\mathrm{dp}}$ - daily inflow of extraneous waters into a sewage system, $\mathrm{m}^{3} \cdot \mathrm{d}^{-1}$,

$\mathrm{Q}_{\mathrm{dm}}$ - daily inflow of a mixture of municipal wastewater and extraneous waters during wet weather, $\mathrm{m}^{3} \cdot \mathrm{d}^{-1}$,

$\mathrm{Q}_{\mathrm{ds}}$ - average daily inflow of municipal wastewater (without extraneous waters) during dry weather, $\mathrm{m}^{3 \cdot} \mathrm{d}^{-1}$

The second parameter is $U_{w p}$ (the share of extraneous waters). It determines the percentage of extraneous waters in the total volume of the municipal sewage mixture along with extraneous waters [10]. The $U_{w p}$ parameter was calculated according to the formula (2).

$$
U_{w p}=\left(Q_{d p} / Q_{d m}\right) \cdot 100
$$

where:

$\mathrm{U}_{\mathrm{wp}}$ - daily share of extraneous waters in wastewater draining from the sewage system, $\%$,

$\mathrm{Q}_{\mathrm{dp}}$ - daily inflow of extraneous waters to the sewage system, $\mathrm{m}^{3} \cdot \mathrm{d}^{-1}$,

$\mathrm{Q}_{\mathrm{dm}}$ - daily inflow of a mixture of proper wastewater and extraneous waters during wet weather to the sewage system, $\mathrm{m}^{3} \cdot \mathrm{d}^{-1}$.

Due to the fact that the total retention of wastewater in the treatment plant and in the sewage network lasts about 24 hours, the daily precipitation is assigned to the amount of wastewater that flows the next day [11].

\subsection{Statistical analysis}

In order to determine whether there is a variation in the variability in the $\mathrm{Q}$ wastewater inflow in individual categories characterizing the amount of precipitation, the one-way ANOVA was used. As a comparative group, data illustrating the variability of $\mathrm{Q}$ wastewater inflow during rainless days (dry weather) was used. Collection of data after the Box-Cox transformation is characterized by normal distribution and homogeneous variance. The categories characterizing the amount of precipitation were adopted as independent variables. The analysis was carried out for four sets of categories covering from 2 to 11 categories corresponding to particular ranges of precipitation. The results of the analysis of variance indicate that there is a statistically significant diversity of $Q$ variations for the majority of the analyzed categories. In order to determine the percentage of the variance of the analyzed data directly related to the precipitation category, the following dependence was used:

$$
\omega^{2}=\frac{S S_{\text {effect }}-d f_{\text {effect }}\left(M S_{\text {error }}\right)}{M S_{\text {error }}+S S_{\text {total }}} \cdot 100 \%
$$

where; $\omega^{2}$ - estimator of variance for the dependent variable explained by an independent variable in the entire data population,

$\mathrm{SS}_{\text {effect }}$ - sum of squares associated with an effect

$\mathrm{df}_{\text {effect }}-$ degrees of freedom associated with an effect,

$\mathrm{MS}_{\text {error }}-$ mean square of an error,

$\mathrm{SS}_{\text {total }}-$ total sum of squares.

\subsection{Characteristics of the sewerage system}

The sewage system in Nowy Targ has a length of 86.9 $\mathrm{km}$. The sewer network works in the gravitational system and only $1.7 \mathrm{~km}$ of sewer lines are in the pressure system. The sewage network is made of PVC pipes and stoneware with DN diameters from 200 to $400 \mathrm{~mm}$. The sewage network is a sanitary network and is intended for the collection of domestic sewage. Currently, approximately 4,800 residential buildings, public buildings and service facilities are connected to the sewer system. In addition, 60 legally operating furrier production facility are connected to the sewage system, from which industrial wastewater is discharged. In addition, wastewater from the tannery, which is difficult to estimate, is discharged into the sewer network [1213]. Domestic sewage and wastewater flows into the collective mechanical-biological sewage treatment plant with the designed capacity Qśr.d. $=21,000 \mathrm{~m}^{3 \cdot} \mathrm{d}^{-1}$ and assumed in the project $\mathrm{PE}=116,000$ inhabitants.

\section{Results and discussion}

In the first stage of the analysis, the amount of wastewater inflowing in rainless weather (dry weather) was characterized. Based on the recommendations proposed by Kaczor [7], 77 days were generated from a group of 731 analyzed days. During these days, there was no precipitation or the precipitation was less than 1 $\mathrm{mm}$ in the 5 preceding days. In the analyzed period of research, the average sewage inflow amounted to 12323 $\mathrm{m}^{3} \cdot \mathrm{d}^{-1}$. The variability of wastewater inflow in dry weather described by the coefficient of variation was $\mathrm{CV}$ $=11 \%$. This indicates a small diversity of wastewater inflow in this period according to the scale proposed by Mucha [14]. In comparison to the inflow, for which the sewage treatment plant was designed and made, the actual inflow during dry days was $41 \%$ lower. Characteristic amounts of wastewater inflow in dry weather are presented in Table 1.

\begin{tabular}{|c|c|c|c|c|c|}
\hline \multicolumn{6}{|c|}{ Statistics for $\mathrm{Q}_{\text {śr.d. }}$} \\
\hline 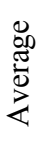 & : & $\dot{\Xi}$ & 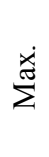 & 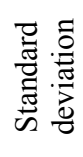 & 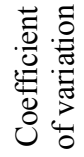 \\
\hline \multicolumn{5}{|c|}{$\mathrm{m}^{3} \cdot \mathrm{d}^{-1}$} & $\%$ \\
\hline
\end{tabular}

Table 1. Statistical chracteristics of the wastewatyer inflow $\mathrm{Q}_{\text {sr.d. }}$ in dry weather. 


\begin{tabular}{|l|l|l|l|l|l|}
\hline 12323 & 11924 & 9450 & 16346 & 1382.9 & 11 \\
\hline
\end{tabular}

In the next stage of the analysis, based on the average daily wastewater inflow in rainless weather, the average daily inflow of rainwater during days with precipitation was calculated. In the case of days with precipitation (from 0.1 to $5.0 \mathrm{~mm} \cdot \mathrm{d}^{-1}$ ), it was found that the average inflow of rainwater to the treatment plant was $2038 \mathrm{~m}^{3} \cdot \mathrm{d}^{-}$ ${ }^{1}$. In the case of days with precipitation from 5.1 to 10 $\mathrm{mm} \cdot \mathrm{d}^{-1}$, the amount of rainwater amounted to $2979 \mathrm{~m}^{3} \cdot \mathrm{d}^{-}$ ${ }^{1}$. During days with precipitation in the range from 10.1 to $15.0 \mathrm{~mm} \cdot \mathrm{d}^{-1}$, the amount of rainwater in the sewage system was $3136 \mathrm{~m}^{3} \cdot \mathrm{d}^{-1}$. In the next range, when precipitation oscillated from 15.1 to $20.0 \mathrm{~mm} \cdot \mathrm{d}^{-1}$, the amount of rainwater was $5070 \mathrm{~m}^{3} \cdot \mathrm{d}^{-1}$. In the last of the analyzed periods, when the precipitation in the sewage basin was over $20.0 \mathrm{~mm} \cdot \mathrm{d}^{-1}$, rainwater inflow increased to the level of $5925 \mathrm{~m}^{3} \cdot \mathrm{d}^{-1}$. The average daily rainwater inflow during days with the characteristic precipitation is shown in Figure 1.

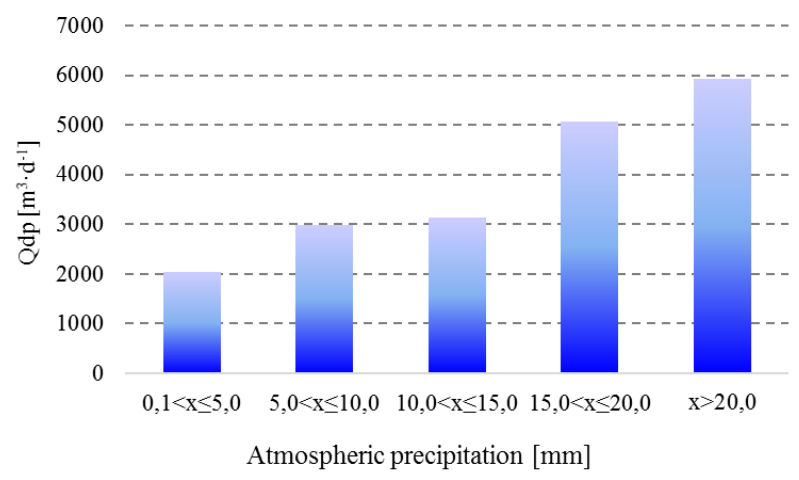

Fig. 1. Volume of extraneous waters (rainwater) flowing into the treatment plant against the precipitation in individual groups.

On the basis of the formula (2), the percentage share of Uwp (\%) for rainwater in the total mixture of wastewater flowing into the treatment plant in days with precipitation was calculated. During days with precipitation oscillating from 0.1 to $5.0 \mathrm{~mm} \cdot \mathrm{d}^{-1}$, the share of extraneous waters in the total amount of wastewater amounted to (average) 14.2\%. During days with precipitation oscillating from the level of 5.1 to 10.0 $\mathrm{mm} \cdot \mathrm{d}^{-1}$, the amount of extraneous water accounted to $19.5 \%$ of the total amount of wastewater. During days with precipitation ranging from 10.1 to $15.0 \mathrm{~mm} \cdot \mathrm{d}^{-1}$, the amount of rainwater amounted to $20.3 \%$ in the total amount of wastewater. In the range of precipitation from 15.1 to 20.0 , extraneous waters in the total mixture of inflowing wastewater constituted $29.2 \%$. During days with precipitation in the sewage basin exceeding 20 $\mathrm{mm} \cdot \mathrm{d}^{-1}$, the share of extraneous waters (rainwater) in the total amount of wastewater was $32.5 \%$. Individual shares of rainwater in the total amount of wastewater flowing into the treatment plant are presented in Figure 2.

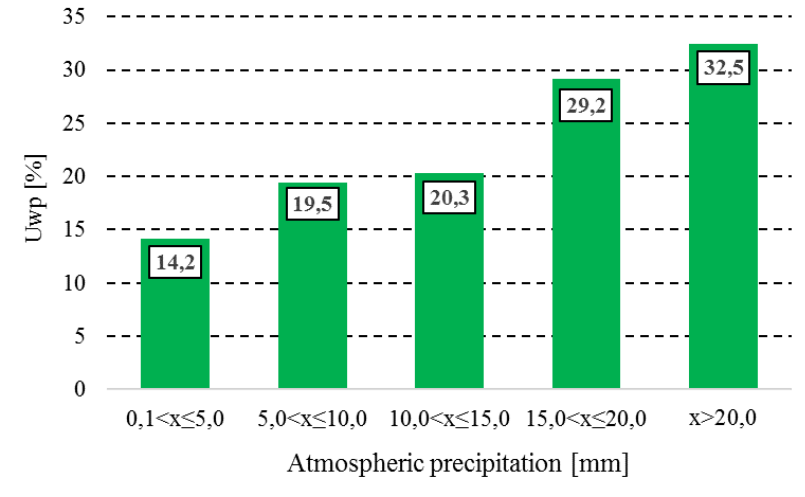

Fig. 2. Percentage of rainwater in the total amount of wastewater flowing into the treatment plant during the period of characteristic precipitation

Based on the results of statistical analysis concerning the occurrence of variations in the variability of $\mathrm{Q}$ wastewater inflow in individual categories characterizing the amount of precipitation, it was found that $\omega^{2}$ values indicate that only a small part of $\mathrm{Q}$ variations is directly related to the category of precipitation (Table 2).

Table 2. Explained variance of the dependent variable presented in $\%$

\begin{tabular}{|c|c|c|c|c|}
\hline Number of categories & 2 & 3 & 6 & 11 \\
\hline \hline$\omega^{2}$ & 5.41 & 7.51 & 8.29 & 9.87 \\
\hline
\end{tabular}

With an increase in the number of precipitation categories, there is no statistically significant differentiation between $\mathrm{Q}$ and individual precipitation categories. This was determined with the use of the Tukey's test for sets with unequal numbers (Unequal N HSD test). Simultaneously, along with the increasing number of categories, the value of $\omega^{2}$ increases - this may indicate the increasingly random nature of $\mathrm{Q}$ variation along with narrowing the ranges of precipitation.

The obtained results show that in the sewage system in Nowy Targ (during the precipitation period), a significant share of wastewater flowing into the treatment plant constitutes the so-called extraneous waters. Similar research results were obtained by Kaczor [7] and Chmielowski [8]. They stated that this phenomenon is caused by the inflow of extraneous waters. Moreover, the above-mentioned authors indicate that this phenomenon has an adverse effect in terms of the efficiency of the wastewater treatment processes and in economic terms, because it increases the cost of wastewater treatment. Therefore, as recommended by Kaczor [15], it is necessary to eliminate the cause of this phenomenon, repair improperly made manholes of sewer manholes, which cause that rainwater enters the sewer collectors. Another equally important reason for the entry of rainwater into the sewer systems is illegally connected drain pipe for rainwater. This type of phenomenon in the analyzed sewage system should be 
diagnosed and eliminated. This will enable to limit the flow of rainwater to the treatment plant [2, 16-17].

\section{Conclusion}

The conducted research concerning the impact of precipitation on the amount of wastewater generated in the sewage system in Nowy Targ confirmed that extraneous waters (rainwater), entering the sewage system during precipitation, constitute a significant share of the total amount of wastewater flowing into the treatment plant. During the days with precipitation oscillating at the level of $10 \mathrm{dm}^{3}$ per $\mathrm{m}^{2}$ per day, there is about $20 \%$ more rainwater in wastewater flowing into the treatment plant (i.e. approx. $3000 \mathrm{~m}^{3}$ of wastewater per day) compared to days without precipitation. During the period of heavy rains, i.e. greater than $20 \mathrm{dm}^{3}$ per $\mathrm{m}^{2}$ per day, the share of rainwater in the total amount of wastewater oscillates within $30 \%$ - this constitutes about $6000 \mathrm{~m}^{3}$ more wastewater per day than in the so-called dry period. Therefore, immediate actions should be taken to eliminate the causes of inflows of extraneous waters (rainwater) to the sewage system. This will reduce the cost of wastewater treatment and improve the efficiency of the treatment plant. Consequently, this ensures a better quality of wastewater discharged to the receiver i.e. the River Dunajec.

\section{Acknowledgements}

Publication is funded by the Polish National Agency for Academic Exchange under the International Academic Partnerships Programme from the project ,Organization of the 9th International Scientific and Technical Conference entitled Environmental Engineering, Photogrammetry, Geoinformatics - Modern Technologies and Development Perspectives".

\section{References}

1. H. Bauman-Kaszubska, M. Sikorski, J. Wat. L. Develop. 13b, 149 (2009)

2. D. Młyński, K. Chmielowski, A. Młyńska, J. Wat. L. Develop. 28, 61 (2016)

3. D. Butler, J.W. Davies, Urban Drainage. 3rd Edition. Spon Press an imprint of Taylor \& Francis, London and New York (2011)

4. G. Kaczor, K. Chmielowski, P. Bugajski, Ann. Set The Environ. Protec. 19, 668 (2017)

5. E. K. McMahan, Impacts of Rainfall Events on Wastewater Treatment Processes. Graduate Theses and Dissertations (2006)

6. K. Pawęska, P. Duda, Inż. Ekol. 19/6, 49 (2018)

7. G. Kaczor, 2012. Effect of infiltration and inflow waters on the performance of small sewer systems. Zeszyty Naukowe Uniwersytetu Rolniczego w Krakowie, 495, (2012)

8. K. Chmielowski, Acta Sci. Pol., For. Circum. 18(2), 39 (2019)
9. G. B. Kaczor, K. Chmielowski, P. Bugajski, J. Wat. L. Develop. 33, 73 (2017)

10. R. Pecher, Korresp. Abwas. 12, 2250 (1998)

11. E. Nowobilska-Majewska, P. Bugajski. J. Ecol. Eng. 20(8), 135 (2019)

12. E. Nowobilska-Majewska. Ecol. Eng. 18(6), 30, (2017)

13. E. Nowobilska-Majewska, P. Bugajski. E3S Web of Conferences 86, 00024 (2019).

14. J. Mucha, Skrypt, Katedra Geologii Kopalnianej, AGH Kraków, 155 (1994)

15. G. Kaczor, Infra. i Ekol. Ter. Wiej. 9, 155 (2009)

16. J. Łomotowski, A. Szpindor, Nowoczesne systemy oczyszczania ścieków. Arkady Warszawa (1999)

17. C. Karpf, P. Krebs. Assessment of Extraneous Water Inflow in Separated Sewer Networks. Proc.10th ICUD Conference, Copenhagen, Danmark, (2005) 